\author{
B.E. Wildhaber $\cdot$ K.N. Lynn $\cdot$ H. Yang \\ D.H. Teitelbaum
}

\title{
Total parenteral nutrition-induced apoptosis in mouse intestinal epithelium: regulation by the Bcl-2 protein family
}

Accepted: 28 November 2001 / Published online: 26 September 2002

(C) Springer-Verlag 2002

\begin{abstract}
Apoptosis of intestinal epithelial cells (EC) plays a role in total parenteral nutrition (TPN)-induced villus atrophy. Among the mediators of apoptosis in EC are some members of the Bcl-2 family of proteins. Bcl-2 members can either be anti- $\left(\mathrm{Bcl}-2, \mathrm{Bcl}-\mathrm{x}_{\mathrm{L}}, \mathrm{Bcl}-\mathrm{w}\right)$ or pro-apoptotic (Bax, Bak, Bid, Bad, Bcl- $\mathrm{x}_{\mathrm{S}}$ ). To determine whether the observed increase in apoptosis induced by TPN is associated with an alteration in these Bcl-2 members' mRNA expression, mice were randomized to either TPN or oral feeding (controls). Animals were killed after 7 days and the intestine was harvested. EC were purified with magnetic beads. Apoptosis was detected by cell-surface expression of phosphatidylserine using flow cytometry. EC mRNA expression was determined by reverse-transcriptase polymerase chain reaction. Results were expressed relative to $\beta$-actin. TPN resulted in a significant $(P<0.05$, unpaired $t$-test $)$ increase in apoptosis: TPN $29.4 \pm 11.3 \%$ versus control $14.4 \pm 5.1 \%$. The expression of the pro-apoptotic members Bax, Bak, Bid, and Bcl- $\mathrm{x}_{\mathrm{S}}$ was significantly $(P$ $<0.05)$ decreased after TPN. In contrast, a significant increase was observed in the anti-apoptotic member Bcl2. mRNA expression of Bcl-w, Bad, and Bcl- $\mathrm{x}_{\mathrm{L}}$ was not significantly different between the control and TPN groups. Thus TPN-induced apoptosis was associated with an increased expression of anti-apoptotic factors and a decrease in pro-apoptotic factors. This contrasts with other reports where these factors showed converse effects under apoptotic conditions. Our results may demonstrate a unique regulatory pathway that may
\end{abstract}

B.E. Wildhaber $\cdot$ K.N. Lynn $\cdot$ H. Yang $\cdot$ D.H. Teitelbaum $(\bowtie)$ Section of Pediatric Surgery, Department of Surgery,

University of Michigan Medical School and C.S. Mott Children's Hospital, Ann Arbor, MI 48109, USA

E-mail: dttlbm@umich.edu

Tel.: + 1-734-7646482

Fax: + 1-734-9369784

D.H. Teitelbaum

Section of Pediatric Surgery, University of Michigan Hospitals, Mott F3970, Box 0245, Ann Arbor, MI 48109, USA counter the observed increase in TPN-induced EC apoptosis.

Keywords Apoptosis $\cdot \mathrm{Bcl}-2$ protein family $\cdot$ Intestinal epithelial cells $\cdot$ Total parenteral nutrition

\section{Introduction}

Apoptosis is a unique form of cell death that is essential to allow the normal functions of most biological organisms. Apoptosis of intestinal epithelial cells (EC) plays a role in total parenteral nutrition (TPN)-induced villus atrophy [1]. Two different pathways are known to induce apoptosis in the intestinal tract: (1) activated neurophils; and (2) intestinal intraepithelial lymphocytes (IEL) [2]. The IEL pathway shows different and distinct mechanisms, such as the Fas/FasL system (Fas ligand on IEL, Fas receptor on EC) and secretion of perforin, a pore-forming protein, which results in an intracellular death-inducing signaling cascade in the EC [3,4]. The Fas/FasL system is known to be upregulated by interferon-gamma (IFN- $\gamma)$ [1] or p53, a tumor-suppressor protein $[5,6]$.

A major intracellular signalling pathway for apoptosis is mediated by the $\mathrm{Bcl}-2$ family of proteins. Members of this family can either function to prevent apoptosis $\left(\mathrm{Bcl}-2, \mathrm{Bcl}-\mathrm{x}_{\mathrm{L}}, \mathrm{Bcl}-\mathrm{w}\right)$ or support intracellular apoptotic signalling (Bax, Bak, Bid, Bad, Bcl- $x_{S}$ ). The up- or down-regulation of these proteins has been shown to play a major role in determining whether or not cells will undergo apoptosis [7]. We hypothesized that EC apoptosis with TPN administration would be associated with an increase in pro-apoptotic mRNA expression and decreased expression of anti-apoptotic Bcl-2 members.

\section{Materials and methods}

Male, specific-pathogen-free, 2-month-old mice (C57BL/6J, Jackson Laboratories, Bar Harbor, ME) were maintained under 
temperature, humidity, and light-controlled conditions and were initially fed ad libitum with normal mouse chow and water. Following 2 weeks of acclimation the mice were divided into two groups and received either TPN or oral feeding (controls). To perform IV catheterization they were anesthetized with sodium pentobarbital $(50 \mathrm{mg} / \mathrm{kg}$ body weight IP). During administration of IV solutions, mice were housed in metabolic cages.

A silicon rubber catheter was inserted into the superior vena cava through the left jugular vein. The distal end of the catheter was tunneled subcutaneously. The catheter, exiting between the scapulae, was attached to a swivel spring that allowed mice free movement in their individual cages (Metamount System, Instech, Plymouth Meeting, MA). Catheterized mice were connected to an infusion pump (AIM pain provider pump, donated by Abbott, Abbott Park, IL), and 5\% dextrose in 0.45 saline with $20 \mathrm{~mol} \mathrm{KCl} /$ 1 was infused at an initial rate of $3 \mathrm{ml} / 24 \mathrm{~h}$.

After $12 \mathrm{~h}$ the TPN mice received a solution containing a balanced mixture of amino acids, lipids, and dextrose in addition to electrolytes and vitamins (prepared by the hospital pharmacy) [8]. Caloric delivery was based on estimates of caloric intake by the control group and from previous investigators, and was essentially the same in both groups [9]. The TPN was given at $7 \mathrm{ml} / 24 \mathrm{~h}$ with no oral intake other than water ad libitum.

Control mice received a saline infusion instead of TPN at a rate of $7 \mathrm{ml} / 24 \mathrm{~h}$. In addition, they were given standard laboratory mouse chow and water ad libitum.

Animals in both groups were killed after 7 days using $\mathrm{CO}_{2}$, and the intestine was harvested. Survival in the TPN group was $48.3 \%$, versus $93.30 \%$ in the control group. This low survival was felt to be secondary to the almost $50 \%$ incidence of bacterial translocation seen in rodents on TPN $[10,11]$. All ill-appearing or non-viable animals were not used for this study, which left 8 animals each in the TPN and control groups for analysis of data.

\section{Mucosal cell isolation}

Isolation of mucosal cells was performed using the protocol described by Kiristioglu and Teitelbaum [8]. Mesenteric fat and Peyer's patches were removed from the small intestine, which was then cut longitudinally. The intestine was placed in tissue-culture medium (RPMI 1640 with glutamine) and agitated to remove mucus and fecal material, then cut into $5-\mathrm{mm}$ pieces and washed in an IEL-extraction buffer ( $1 \mathrm{mM}$ EDTA, $1 \mathrm{mM}$ dithiotheritol in phosphate-buffered saline). It was incubated in the same buffer with continuous brisk stirring at $37^{\circ}$ for $20 \mathrm{~min}$. The supernatant was then filtered rapidly through a glass-wool column. After centrifugation, the pellets were purified in $40 \%$ isotonic Percoll (Upjohn \& Pharmacia, Sweden) and reconstituted in tissue-culture medium. The cell suspension contained a purified mixture of EC and IEL at a ratio of 50:50.

\section{Flow cytometry}

Flow cytometry was performed using standard techniques [12]. Acquisition and analysis were performed on a Becton-Dickinson FACScan (Becton-Dickinson, Mountainview, CA) using a Macintosh Power PC computer and CellQuest (Becton-Dickinson) software for analysis.

Separation of EC from IEL was done by gating cells using forward and side-scatter characteristics. Further confirmation of EC and IEL purity was done by specific staining of EC with antibody generated by a hybridoma G8.8 [13] and a pan-lymphoid antibody (anti-CD45, Pharmingen, San Diego, CA). This confirmed purity to exceed $97 \%$. Apoptosis was determined by a flow cytometer based on the cell-surface expression of phosphatidylserine (annexin V), as this is one of the earliest markers of apoptosis. The annexin $\mathrm{V}$ assay was performed with an apoptosis kit (Pharmingen) according to the manufacturer's instruction. Staining with propidium iodide was used to monitor cell necrosis.

\section{Cell separation}

Isolation of purified EC from IEL was performed by direct magnetic separation. Magnetic beads conjugated with antibody to CD45 (specific for lymphoid cells) were used to remove nonepithelial cells. The magnetic bead solution (BioMag SelectaPure Anti-Mouse CD 45R antibody particles, Polyscience, Warrington, PA) was washed three times to remove sodium azide. Cells were resuspended at a concentration of $1 \times 10^{6} / 5 \mathrm{ml}$ RPMI incubated with the magnetic beads $\left(0.11 \mathrm{ml}\right.$ beads for $1 \times 10^{6}$ IEL) for $60 \mathrm{~min}$ on ice, and gently swirled every $10 \mathrm{~min}$ to promote attachment. Magnetic separation was then performed for $10 \mathrm{~min}$ and the supernatant, which contained EC, was saved for RNA isolation. The remaining cells were washed with $5 \mathrm{ml}$ RPMI and again subjected to magnetic separation. The remaining cells bound to the beads were considered purified IEL and were discarded. Using antibody to EC and IEL (see section above), the purity of the magnetically-sorted cells was over $99 \%$.

\section{Reverse-transcriptase polymerase chain reaction (RT-PCR)}

For isolation of total RNA a guanidine isothiocyanate/chloroform extraction method was used. Cells were suspended at a concentration between 2 and $10 \times 10^{6} / \mathrm{ml}$ in tissue-culture media (RPMI 1640 with glutamine) and isolated with Trizol (Gibco BRL, Gaithersburg, MD) according to the manufacturer's directions. RNA was frozen at $-70{ }^{\circ} \mathrm{C}$ until assayed. Quantification was done by spectrophotometry at $260 \mathrm{~nm}$ absorption.

For the RT reaction, EC mRNA (poly A positive) was reversetranscribed into cDNA by adding $2 \mu \mathrm{g} / \mathrm{ml}$ total cellular mRNA to the following reaction mixture: PCR nucleotide mix (BoehringerMannheim, Indianapolis, IN; each at $10 \mathrm{mM}$ ); M-MLV RT (Gibco BRL, $200 \mathrm{U} / \mu \mathrm{l}$ ); Oligo (dT) primer (New England Biolabs, Beverly, MA; $40 \mu \mathrm{M}$ ); and RNAase inhibitor (Roche Diagnostics, Mannheim, Germany, $40 \mathrm{U} / \mu \mathrm{l})$. DEPC-treated $\mathrm{H}_{2} \mathrm{O}$ was added to yield the appropriate final concentration. Samples of $100 \mu \mathrm{l}$ were incubated at $40{ }^{\circ} \mathrm{C}$ for $70 \mathrm{~min}$ and the reaction was stopped by incubating at $95{ }^{\circ} \mathrm{C}$ for $3 \mathrm{~min}$. cDNA samples were stored at $4{ }^{\circ} \mathrm{C}$ until assayed.

For the PCR, specific primers for the anti-apoptotic (Bcl-2, Bcl- $\left.x_{\mathrm{L}}, \mathrm{Bcl}-\mathrm{w}\right)$ and pro-apoptotic (Bax, Bak, Bid, Bad, Bcl- $\mathrm{x}_{\mathrm{S}}$ ) sequences were designed to maximize the efficient PCR product with minimization of false priming sites using an optimization program (OLIGO 4.1, National Biosciences, Plymouth, MN). Their sequences are shown in Table 1. The PCR was run under the following conditions (final concentrations): RT product $(2 \mu \mathrm{l})$; forward and reverse specific oligomers $(5 \mathrm{mM}, 1 \mu \mathrm{l})$; PCR buffer (Roche, Mannheim, $10 \mathrm{mM}$ Tris, $50 \mathrm{mM} \mathrm{KCl}, 0.8 \mu \mathrm{l}$ ); $\mathrm{MgCl}_{2}$ (Roche, Mannheim, $25 \mathrm{mM}, 0.2 \mu \mathrm{l}$ ); and Taq polymerase (PerkinElmer, Foster City, CA, $5 \mathrm{IU} / \mu \mathrm{l}, 0.1 \mu \mathrm{l}$ ), with sufficient DEPCtreated $\mathrm{H}_{2} \mathrm{O}$ to allow for appropriate concentrations. The following thermal cycler (PTC-100, MJ Research, Watertown, MA) settings were used: Step 1: $94{ }^{\circ} \mathrm{C}, 2 \mathrm{~min}$; step 2: $94{ }^{\circ} \mathrm{C}, 15 \mathrm{~s} ; 55^{\circ} \mathrm{C}, 15 \mathrm{~s}$; $72{ }^{\circ} \mathrm{C}, 1 \mathrm{~min}$; step 3: $72{ }^{\circ} \mathrm{C}, 5 \mathrm{~min}$; step $4: 4{ }^{\circ} \mathrm{C}$. To insure that DNA product was generated at the exponential portion of the product curve, the following cycles of step 2 were performed for the various Bcl-2 family members: $36 \times$ step 2 for Bcl- $\mathrm{x}_{\mathrm{L}}$, Bad, and Bcl$\mathrm{x}_{\mathrm{S}}$ and $40 \times 2$ for Bcl-2, Bcl-w, Bax, Bak, and Bid. The PCR products were run out on $2 \%$ agarose gel containing ethidium bromide for $1 \mathrm{~h}$ at $160 \mathrm{~V}$.

A digital image of the cDNA product was recorded with a video camera system under ultraviolet light (Kodak Electrophoresis Documentation and Analysis System [EDAS] DC290 camera, Eastman Kodak, Rochester, NY). Product bands were quantified using an imaging computer program (Kodak 1D Image Analysis Software). Results were expressed as the ratio of the investigated mRNA expression level over the $\beta$-actin mRNA expression level All data were expressed as mean \pm standard deviation. The results were analyzed using an unpaired $t$-test, and statistical significance was defined as $P<0.05$. 
Table 1 Specific primer data for selected Bcl-2 family members

\begin{tabular}{lllll}
\hline Name & $\begin{array}{l}\text { GenBank accession } \\
\text { number }\end{array}$ & $\begin{array}{l}\text { Length of cDNA } \\
\text { product }(\mathrm{bp})\end{array}$ & Forward primer & Reverse primer \\
\hline$\beta$-actin & NM_007393 & 319 & GAG GGA AAT CGT GCG TGA CAT AGA AGG AAG GCT GGA AAA GAG \\
Bcl-2 & AA867214 & 526 & CAC ATC CAA TAA AAG AGC & ACC CCA TCC TGA AGA GTT \\
Bcl-x & L35049 & 399 & AGG CAG GCG ATG AGT TTG AAC GAA CCA CAC CAG CCA CAG TCA \\
Bcl-w & U59746 & 362 & GTT TCC GCC GCA CCT TCT CT & CCC CGT CAG CAC TGT CCT CA \\
Bax & L22472 & 161 & CGG CGA ATT GGA GAT GAA CTG GCA AAG TAG AAG AGG GCA ACC \\
Bak & Y13231 & 349 & AAG ACG CTT TAG CAA ACA GG & TAG GGA GGG CAA GGA TTG TG \\
Bid & U75506 & 477 & GCC AAG CAC ATC ACA GAC CTG GA GA GA ATC ACG GAG CAA AGA T \\
Bad & L37296 & 438 & GGA AGA CGC TAG TGC TAC AG GAG CCT CCT TTG CCC AAG TT \\
Bcl-x & U10100 & 210 & AGG CAG GCG ATG AGT TTG AAC GAA CCA CAC CAG CCA CAG TCA \\
\hline
\end{tabular}

Fig. 1 Flow cytometry detection of epithelial cell (EC) apoptosis: a representative flow-box plot for a control and TPN mouse. Percentage of apoptotic cells expressed as sum of right lower and right upper quadrant. Marked increase of apoptotic EC after TPN (29.4 $\pm 11.3 \%$ ) compared with control $(14.4 \pm 5.1 \%)$
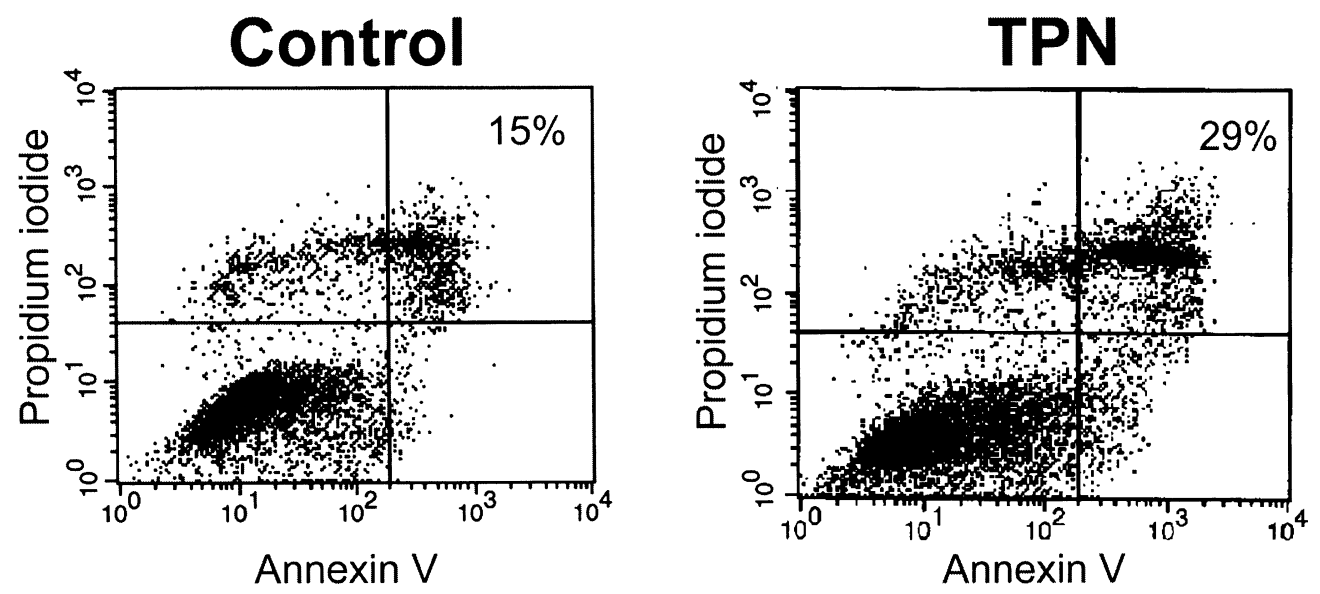

\section{Results}

The average body weight of the animals at the beginning was $23.2 \pm 1.4 \mathrm{~g}$ and $21.4 \pm 2.2 \mathrm{~g}$ for the TPN and control groups, respectively; after the 7-day treatment it was $20.3 \pm 2.1 \mathrm{~g}$ for TPN mice and $21.7 \pm 2.3 \mathrm{~g}$ for control mice.

Cells isolated from the intestine contained an enriched population of IEL with an approximately 50:50 ratio of IEL to EC. Similar to other investigations, there was a statistically significant $(P=0.03)$ decline in the number of IEL with TPN [9]: the cell counts per mouse were $4.9 \pm 2.1 \times 10^{6}$ in TPN mice and $7.0 \pm 1.7 \times 10^{6}$ in the controls. There was also a statistically significant difference in EC counts per mouse between study groups: in TPN mice $3.0 \pm 1.9 \times 10^{6}$ and in controls 6.6 $\pm 2.1 \times 10^{6}(P=0.04)$.

Apoptosis in EC in the small bowel significantly increased $(P=0.02)$ after 7 days of TPN: $29.4 \pm 11.3 \%$ versus $14.4 \pm 5.1 \%$ in controls (Fig. 1). In contrast, the percent of EC showing cell necrosis (propidium iodide staining) was not statistically different between control and TPN mice: TPN $15.4 \pm 13.0 \%$ versus controls 6.8 $\pm 3.1 \%(P=0.19)$.

Table 2 and Fig. 2 summarize the RT-PCR results. In general, and in contrast to our original hypothesis, the mRNA expression of most pro-apoptotic members was significantly $(P<0.05)$ decreased in TPN compared to control mice: Bax declined by $29 \%$, Bid by $88 \%$, Bak by $46 \%$, and $\mathrm{Bcl}-\mathrm{x}_{\mathrm{S}}$ by $95 \%$. In contrast, and again opposed to our original hypothesis, there was a significant increase in the anti-apoptotic member Bcl-2 $(80 \%$ rise) in the TPN group. Other anti-apoptotic members failed to show an appreciable change with TPN.

\section{Discussion}

Apoptosis is a morphologically and biochemically distinct form of cell death that plays an essential biological role to maintain homeostasis and physiological integrity in most tissues. Apoptosis is programmed cell death that evolves under genetic control. It is characterized by stereotypic and morphologic features including cell shrinkage, disappearance of microvilli, externalization of phophatidylserine, condensation of chromatin, nuclear fragmentation, separation of apoptotic cell bodies, and finally, phagocytosis by neighboring and mononuclear cells [14]. The intestinal mucosa has a rapid turnover rate (3-6 days), and constitutively works to maintain an equilibrium between cell proliferation and death. Disregulation of the rate of apoptosis may result in tissue atrophy or in hyperplasia and malignant transformation [15].

Mechanisms of apoptosis vary among different cell types and may involve an array of signaling processes and regulators influencing multiple cellular functions. Generally, apoptosis relies on the activation of cysteine proteases of the caspase family. Caspases (cysteine-de- 
Table 2 mRNA expression of Bcl-2 family members (Results expressed as ratio to $\beta$-actin expression)

\begin{tabular}{|c|c|c|c|c|c|c|c|c|}
\hline Group & \multicolumn{5}{|c|}{ Pro-apoptotic members } & \multicolumn{3}{|c|}{ Anti-apoptotic members } \\
\hline Control & $0.53 \pm 0.11$ & $1.14 \pm 0.12$ & $0.25 \pm 0.12$ & $0.62 \pm 0.14$ & $1.02 \pm 0.10$ & $0.16 \pm 0.17$ & $0.51 \pm 0.24$ & $0.45 \pm 0.11$ \\
\hline
\end{tabular}

${ }^{\mathrm{a}} P<0.05$ control versus TPN
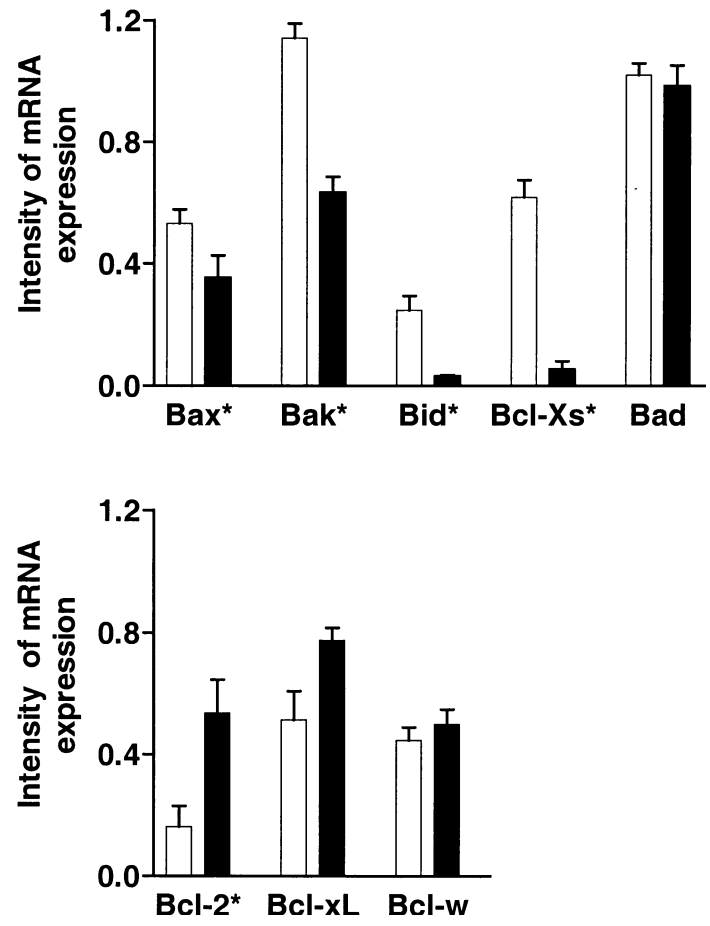

Fig. 2 mRNA expression of Bcl-2 family members for control (white) and TPN (black) groups. Results expressed as ratio to $\beta$-actin expression $* P<0.05$ control vs TPN

pendent, aspartate-specific proteases) are endoproteases that are integral to the disassembly of the cell [16]. This class of proteins cleaves a variety of substrates, including DNA repair enzymes, cellular and nuclear structural proteins, and many other cellular constituents $[17,18]$. There are two main pathways leading to caspase activation, the so called intrinsic and extrinsic pathways. The intrinsic pathway occurs directly in mitochondria after receiving external, mostly non-specific death signals such as chemicals or $\gamma$-irradiation. In response, cytochrome $\mathrm{c}$ is released from the mitochondria, interacts with Apaf- 1 protein and cATP, and activates the deathinducing caspase cascade. The extrinsic pathway is mediated by cell-surface receptors and, in the intestinal tract, includes ligands from IEL. Binding of the IEL's CD95 ligand (FasL) to the CD95 receptor on the EC (Fas) activates the death-inducing signaling complex. In turn, this complex recruits the caspases and leads to apoptosis.

Regulation of the Fas-mediated proteolytic cascade of apoptosis may occur at various steps along the recruitment-activation pathway. In the small-intestinal epithelium, the IEL appears to reserve the potential to up-regulate genetic expression of its FasL and EC Fas. One study that used TPN-induced apoptosis found this up-regulation to coincide with increased IEL-derived IFN- $\gamma$ [1]. Another regulatory factor in the Fas/FasL system is the tumor-suppresser protein $\mathrm{p} 53$, which can initiate apoptosis in response to various environmental or physical stresses $[5,6]$.

At mitochondria-related intrinsic levels, the Bcl-2 family of proteins can regulate the engagement of apoptosis and set a survival threshold. These integral membrane proteins are localized to the nuclear membrane, endoplasmatic reticulum, and outer mitochondrial membranes. Members of this family can either be anti-apoptotic (Bcl-2, Bcl- $\mathrm{x}_{\mathrm{L}}, \mathrm{Bcl}-\mathrm{w}, \mathrm{A} 1, \mathrm{NR}-13$, and mcl-1) or pro-apoptotic (Bax, Bcl- $x_{S}$, Bid, Bak, and Bad) [19]. They can modulate the apoptotic transduction pathway through alteration of the intracellular electrochemical gradient, direct inhibition of caspase activation, or by activating antioxidant mechanisms in the mitochondria that are characteristic of certain apoptotic pathways [20].

Through the formation of homodimers and heterodimers, stoichiometric ratios of specific Bcl-2 members may dictate the cell's fate after receiving a death signal. The anti- or pro-apoptotic action appears to be dependent on several factors, including cell type, apoptotic stimuli, cellular context (cell-cycle dependence), cellular environment (presence of growth factors), or cell location (Bcl-2 is mostly expressed at the base of the colonic crypt, but less in the small intestine, whereas Bax is predominant in the crypts of the small intestine; Bak is strongly expressed at the villus, but only weakly in the crypt) [3]. In many tissues, the Bcl-2/Bax ratio appears to determine the cell's fate, whereby excess Bcl-2 confers survival and excess Bax promotes cell death.

Studies suggest that, following the Fas-mediated apoptotic signal, anti-apoptotic Bcl-2 members may be upregulated and provide complete protection or may show no altered expression, implicating a lack of regulatory influence [21]. Those Fas-mediated cells uninfluenced by Bcl-2 proteins concurrently avoid the mitochondria-dependent death mechanism and are labeled as type I cells. Conversely, type II cell death utilizes the cytochrome-c mechanism, and these cells are susceptible to $\mathrm{Bcl}-2$ regulation $[22,23]$. The predominance of one cell type over the other remains unknown; however, receptor-mediated apoptosis mechanisms appear to be specific to the tissue and/or ligand. Apoptotic cells utilizing p53 have shown, as mentioned above, 
increased expression of Fas and FasL, but also up-regulation of Bax and down-regulation of Bcl-2 [5, 6, 24].

Assays of the intestinal epithelium after spontaneous, $\gamma$-radiation-induced and 5-fluorouracil-induced apoptosis resulted in unchanged Bcl-2 expression levels, which indicate its insignificant role in the apoptotic mechanism utilized. Under the same stimuli, the apoptotic response of Bax-null mice suggested that Bax also plays a minor role in the small intestine $[25,26]$. Bak has been shown to be a major endogenous promoter of apoptosis in the gastrointestinal tract [27]. Another report correlated Bax and Bak-double deficient mice with marked inhibition of apoptosis, which suggested that either Bax, Bak, or both appear to be an essential gateway to the mitochondrial dysfunction required for apoptosis in response to diverse stimuli [28]. As for the Bcl-w apoptotic inhibitor, mucosal cells that were Bcl-w-null displayed up to sixfold enhancement of apoptosis after apoptotic induction [29]. The two described pathways can compete with each other, and can be activated sequentially or independently.

In our mouse TPN model, apoptosis significantly increased in TPN animals. Concomitant with this rise in TPN-associated apoptosis was a significant increase in the mRNA expression of $\mathrm{Bcl}-2$ (anti-apoptotic) and a decrease of Bax, Bak, Bid, and Bcl- $x_{S}$ (all pro-apoptotic). This is in contrast to other reports, where these factors showed converse effects under apoptotic conditions. The observed changes in the expression pattern of the Bcl-2 family members is highly suggestive that the Bcl-2 family acts as a counterregulatory mechanism to inhibit ongoing apoptosis due to another mechanism. The EC-neighboring IEL can regulate apoptosis by expression of cytokines. In an earlier study, we showed increased expression of IFN- $\gamma$ by IEL in a mouse TPN model [8]. IFN- $\gamma$ has been reported to have substantial effects on EC growth [30] and to promote the apoptotic process via up-regulation of Fas/FasL [31]. We have also previously shown that TPN-associated villus atrophy is associated with an increase in FasL expression, and this expression appears to be dependent upon the expression of IFN- $\gamma$ [1]. It can be concluded that the extrinsic pathway of apoptosis is up-regulated under TPN conditions.

Several other factors and conditions are known to regulate apoptosis. Intestinal trefoil factor, expressed by goblet cells, has a strong anti-apoptotic action [32]. Short-chain fatty acids also regulate apoptosis via $\beta$-oxidation in the mitochondria [2]. Carcinoembryonic antigen functions as a general inhibitor of apoptosis [33]. In a mouse $50 \%$ small-bowel resection model, it was found that after orogastric application of epidermal growth factor the apoptotic index was increased. Furthermore, keratinocyte growth factor is reported to be a mitogenic growth factor, and is believed to have a critical role in intestinal epithelial growth and maintenance $[34,35]$. Tumor growth factor- $\beta$ also appears to contribute to inhibition of proliferative cell activity [36]. Lastly, tumor necrosis factor was found to induce apoptosis of villus EC in mice [37]. It is possible that some of these additional factors may play a role in the regulation of apoptosis with TPN administration. However, their mechanism has not yet been revealed.

Our results show that the intrinsic pathway, with its regulation by the Bcl-2 family of proteins, was altered in the opposite way than it would be hypothesized: the mRNA levels of the pro-apoptotic members decreased, while those of the anti-apoptotic members increased. The most plausible explanation for this finding is that in the TPN model, the intrinsic pathway is set to counteract the predominantly activated Fas/FasL-mediated extrinsic pathway. Our results may demonstrate an unknown, unique regulatory pathway that appears to act as a means to counter Fas/FasL-mediated apoptosis during the administration of TPN. Clearly, further investigation is needed to define the regulation of this special apoptotic state more clearly.

Acknowledgements This work was supported by a grant from the United States National Institute of Health (AI44076-01) and a fellowship from the Stiftung Novartis Schweiz, the Schweizerische Kinderchirurgische Gesellschaft, and A.G. Coran, Head of the Department of Pediatric Surgery, Ann Arbor, MI.

\section{References}

1. Yang H, Fan Y, Teitelbaum DH (2001) Interferon-gamma mediates epithelial cell apoptosis through a Fas/FasL interaction in a mouse model of total parenteral nutrition (TPN). Gastroenterology 120: A676

2. Tarnawski AS, Szabo I (2001) Apoptosis-programmed cell death and its relevance to gastrointestinal epithelium: survival signal from the matrix. Gastroenterology 120: 294-299

3. Watson A (1999) The role of Fas in apoptosis induced by anticancer drugs. Hepatology 29: 280-281

4. Inagaki-Ohara K, Nishimura H, Sakai T, Lynch DH, Yoshikai Y (1997) Potential for involvement of Fas antigen/Fas ligand interaction in apoptosis of epithelial cells by intraepithelial lymphocytes in murine small intestine. Lab Invest 77: 421-429

5. Muller M, Scaffidi CA, Galle PR, Stremmel W, Krammer PH (1998) The role of p53 and the CD95 (APO-1/Fas) death system in chemotherapy-induced apoptosis. Eur Cytokine Netw 9: 685-686

6. Muller M, Wilder S, Bannasch D, Israeli D, Lehlbach K, Li-Weber M, et al (1998) p53 activates the CD95 (APO-1/Fas) gene in response to DNA damage by anticancer drugs. J Exp Med 188: 2033-2045

7. Ciccocioppo R, Di Sabatino A, Gasbarrini G, Corazza GR (1999) Apoptosis and gastrointestinal tract [review]. Ital J Gastroenterol Hepatol 31: 162-172

8. Kiristioglu I, Teitelbaum DH (1998) Alteration of the intestinal intraepithelial lymphocytes during total parenteral nutrition. J Surg Res 79: 91-96

9. Li JS, Gu SN, Han JM (1988) Total parenteral nutrition induced cholestatic cholecystitis. Chung Hua Wai Ko Tsa Chih 26: 98-100, 125-126

10. Zaloga GP, Roberts P, Black KW, Prielipp R (1993) Gut bacterial translocation/dissemination explains the increased mortality produced by parenteral nutrition following methotrexate. Circ Shock 39: 263-268

11. Alverdy JC, Aoys E, Moss GS (1988) Total parenteral nutrition promotes bacterial translocation from the gut. Surgery 104: $185-190$

12. Shapiro H (1988) Practical flow cytometry, 2nd edn. Alan R. Liss, New York, pp 109-298 
13. Farr A, Nelson A, Truex J, Hosier S (1991) Epithelial heterogeneity in the murine thymus: a cell surface glycoprotein expressed by subcapsular and medullary epithelium. J Histochem Cytochem 39: 645-653

14. Jones BA, Gores GJ (1997) Physiology and pathophysiology of apoptosis in epithelial cells of the liver, pancreas, and intestine. Am J Physiol 273: G1174-1188

15. Hall PA, Coates PJ, Ansari B, Hopwood D (1994) Regulation of cell number in the mammalian gastrointestinal tract: the importance of apoptosis. J Cell Sci 107: 3569-3577

16. Stennicke HR, Salvesen GS (2000) Caspases - controlling intracellular signals by protease zymogen activation. Biochim Biophys Acta 1477: 299-306

17. Cohen GM (1997) Caspases: the executioners of apoptosis. Biochem J 326: 1-16

18. Rosen A, Casciola-Rosen L (1997) Macromolecular substrates for the ICE-like proteases during apoptosis. J Cell Biochem 64: $50-54$

19. Gajewski TF, Thompson CB (1996) Apoptosis meets signal transduction: elimination of a BAD influence. Cell 87: 589-592

20. Lopczynski W, H. ZS Antioxidants, programmed cell death, and cancer. Nutr Res 21: 295-307

21. Varadhachary AS, Salgame P (1998) CD95 mediated T cell apoptosis and its relevance to immune deviation. Oncogene 17: 3271-3276

22. Nagata S (1994) Fas and Fas ligand: a death factor and its receptor. Adv Immunol 57: 129-144

23. Scaffidi C, Fulda S, Srinivasan A, Friesen C, Li F, Tomaselli KJ, et al (1998) Two CD95 (APO-1/Fas) signaling pathways. Embo J 17: 1675-1687

24. Watson AJ (1997) The role of apoptosis in intestinal disease. J Gastroenterol 32: 414-423

25. Merritt AJ, Potten CS, Watson AJ, Loh DY, Nakayama K, Hickman JA (1995) Differential expression of bcl-2 in intestinal epithelia. Correlation with attenuation of apoptosis in colonic crypts and the incidence of colonic neoplasia. J Cell Sci 108: 2261-2271

26. Pritchard DM, Potten CS, Korsmeyer SJ, Roberts S, Hickman JA (1999) Damage-induced apoptosis in intestinal epithelia from bcl-2-null and bax-null mice: investigations of the mechanistic determinants of epithelial apoptosis in vivo. Oncogene 18: 7287-7293
27. Kondo S, Shinomura Y, Miyazaki Y, Kiyohara T, Tsutsui S, Kitamura S, et al (2000) Mutations of the bak gene in human gastric and colorectal cancers. Cancer Res 60: 4328-4330

28. Wei MC, Zong WX, Cheng EH, Lindsten T, Panoutsakopoulou V, Ross AJ, et al (2001) Proapoptotic BAX and BAK: a requisite gateway to mitochondrial dysfunction and death. Science 292: 727-730

29. Pritchard DM, Print C, O'Reilly L, Adams JM, Potten CS, Hickman JA (2000) Bcl-w is an important determinant of damage-induced apoptosis in epithelia of small and large intestine. Oncogene 19: 3955-3959

30. Barrett T, Gajewski T, Danielpour D, Chang E, Beagley K, Bluestone J (1992) Differential function of intestinal intraepithelial lymphocyte subsets. J Immunol 149: 1124-1130

31. Abreu-Martin MT, Palladino AA, Faris M, Carramanzana NM, Nel AE, Targan SR (1999) Fas activates the JNK pathway in human colonic epithelial cells: lack of a direct role in apoptosis. Am J Physiol 276: G599-605

32. Taupin DR, Kinoshita K, Podolsky DK (2000) Intestinal trefoil factor confers colonic epithelial resistance to apoptosis. Proc Natl Acad Sci USA 97: 799-804

33. Ordonez C, Screaton RA, Ilantzis C, Stanners CP (2000) Human carcinoembryonic antigen functions as a general inhibitor of anoikis. Cancer Res 60: 3419-3424

34. Housley R, Morris C, Boyle W, Ring B, Biltz R, Tarpley J, et al (1994) Keratinocyte growth factor induces proliferation of hepatocytes and epithelial cells throughout the rat gastrointestinal tract. J Clin Invest 94: 1764-1777

35. Antony PA, Yang H, Fan Y, Teitelbaum DH (2000) Altered expression of intraepithelial lymphocytes (IEL) keratinocyte growth (KGF) mRNA in the mouse. Gastroenterology 118 : 685

36. Ebert E (1990) Intra-epithelial lymphocytes: interferon-gamma production and suppressor/cytotoxic activities. Clin Exp Immunol 82: 81-85

37. Guy-Grand D, DiSanto JP, Henchoz P, Malassis-Seris M, Vassalli P (1998) Small bowel enteropathy: role of intraepithelial lymphocytes and of cytokines (IL-12, IFN-gamma, TNF) in the induction of epithelial cell death and renewal. Eur J Immunol 28: 730-744 